\title{
Produção do espaço urbano: Análise sobre a oferta de serviços e equipamentos públicos em novas áreas habitacionais de interesse social em Ituiutaba-MG ${ }^{1}$
}

\begin{abstract}
Urban space production: Analysis of the offer of services and equipment public in new housing areas of social interest in Ituiutaba-MG

Producción del espacio urbano: Análisis de la oferta de servicios y equipamientos públicos em nuevas áreas de interés social em Ituiutaba-MG
\end{abstract}

Daniel de Araujo Silva

(PPGEP/UFU/FACIP)

silva.d.a@live.com

Fábio Reis Venceslau

(PPGEP/UFU/FACIP)

vennceslau@hotmail.com

\section{Fausto Amador Alves Neto}

(PPGEP/UFU/FACIP)

fausto.alvesneto@gmail.com

\footnotetext{
${ }^{1}$ Este trabalho é resultado das discussões estabelecidas no Grupo de Pesquisa Observatório das Cidades do curso de Geografia da Faculdade de Ciências Integradas do Pontal (FACIP), Universidade Federal de Uberlândia (UFU), sobretudo no Projeto de Pesquisa de Demanda Universal financiado pela Fundação de Amparo à Pesquisa do Estado de Minas Gerais: Produção do espaço público: formas usos e funções no contexto da cidade contemporânea. Assim como, as atividades realizadas como discentes no Programa de Pós-graduação em Geografia do Pontal (PPGEP).
} 


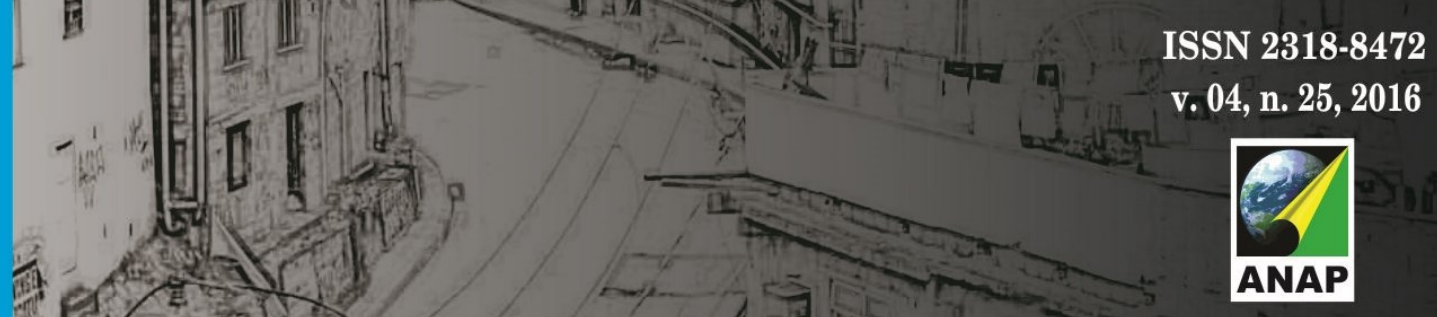

Revista Nacional de Gerenciamento de Cidades

\section{INTRODUÇÃO}

A produção do espaço urbano envolve vários agentes responsáveis por sua produção, dentre eles o Estado. Este, principalmente nos programas habitacionais, como por exemplo, o programa do Governo Federal "Minha Casa Minha Vida (MCMV)". De acordo com Chaves e Neto $(2014$, p. 9) este programa é um "processo recente brasileiro, o programa MCMV, é considerado uma das principais ações do governo de Luís Inácio Lula da Silva (2003-2010), para solucionar o problema habitacional do país", programa este que é considerado um avanço em relação às questões habitacionais no Brasil, porém, o programa ainda é alvo de críticas por vários elementos e aspectos que envolvem sua consolidação enquanto estrutura de moradia. Todavia, de certa forma, cumpre seu papel de contemplar milhares de pessoas com o "sonho da casa própria" e amenizar problemas de cunho social, como o déficit habitacional.

Entretanto, nossa preocupação neste artigo é de uma analise sobre as unidades do MCMV, no que tange ao entorno desses conjuntos habitacionais, como a oferta de serviços públicos e equipamentos urbanos. Visto que a maioria desses conjuntos é implantada nas áreas periféricas em relação ao centro, e em uma cidade do tipo monocêntrica, como Ituiutaba, a distância do centro se torna um problema para a maioria das pessoas, pois nem todos dispõem de meios de transportes particulares para se locomoverem pela cidade.

Assim, o presente artigo teve como objetivo analisar os novos conjuntos habitacionais na cidade de Ituiutaba quanto à presença de equipamentos e serviços públicos. Como recorte espacial foi apontado o total de seis bairros (Figura 1), a saber: Residenciais Canaã I e II; Residencial Buritis; Residencial Marcondes Bernardes e Residencial Nadime Derze I e II, todos pertencentes ao programa MCMV.

Para tal análise, percorremos os referidos conjuntos habitacionais observando, fotografando e analisando as estruturas dos locais, levando em consideração a presença ou a falta de serviços e equipamentos públicos urbanos como: escolas, espaços de lazer, postos de saúde, acessibilidade e transporte coletivo, além de calcular a distância a se percorrer pelos moradores para terem esses serviços em outros bairros. Ainda para o desenvolvimento da parte teórica da pesquisa foi feito levantamento bibliográfico sobre a temática abordada, bem como o levantamento cartográfico da cidade de Ituiutaba e dos bairros em questão. 


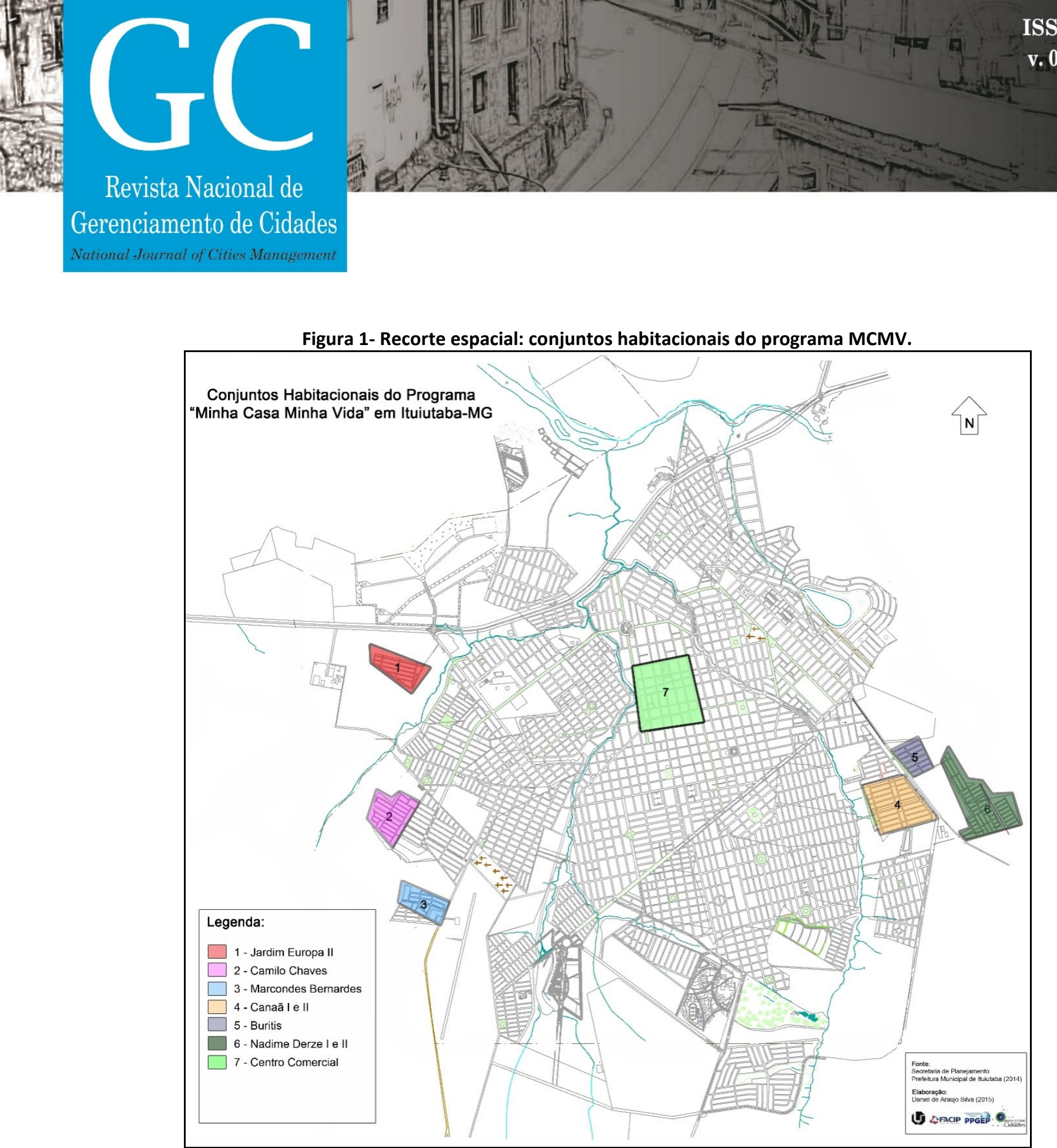

Fonte: Pref. Mun. Ituiutaba (2014). Org.: Daniel de Araujo Silva (2015).

\section{APONTAMENTOS TEÓRICOS}

Diante da consolidação das relações sociais sob a perspectiva da dimensão espacial, a construção da sociedade deve ser entendida a partir dos conceitos da chamada produção/reprodução do espaço. A relação estabelecida entre o homem social e o espaço por ele ocupado denota uma relação dialética, da qual se percebe nítida apropriação do espaço em si mesmo em determinado momento histórico definido (CARLOS, SOUZA e SPOSITO, 2011). É importante trazer que a produção das relações de forma geral ligadas ao espaço ultrapassa a questão da produção e circulação de mercadorias e serviços e acaba abrangendo questões mais específicas como a habitação, vida privada, lazer, dentre outros, como se percebe nos ensinamentos de Carlos, Souza e Sposito (2011, p. 56), 


\begin{abstract}
Em sentidos mais profundos, a produção de relações mais abrangentes, e no plano espacial, significa neste contexto o que se passa fora do âmbito específico da produção de mercadorias e do mundo do trabalho (sem, todavia, deixar de incorporá-lo), para estender-se ao plano do habitar, do lazer e da vida privada, expandindo sua exploração pela incorporação de espaços cada vez mais amplos. Assim, se o espaço é condição da realização do processo produtivo, unindo os atos de distribuição, troca e consumo de mercadorias, ele se produz como materialidade - como, por exemplo, infraestrutura viária, rede de água, luz e esgoto e etc (CARLOS, SOUZA e SPOSITO, 2011, p. 56).
\end{abstract}

Nesse pensamento, é possível verificar que o espaço, enquanto precursor do processo produtivo se remonta a partir da materialidade declinada no próprio contexto espacial, de forma que é necessária a percepção de infraestruturas mínimas para vivência em sociedade.

Salienta-se que após a Revolução Industrial, surgiu um processo de urbanização tanto no cenário mundial como no brasileiro, fazendo-se emergir inúmeros questionamentos sobre os problemas ligados a organização e estruturação desse novo espaço explorado. (MENDONÇA, 2004).

Não obstante isto, dentre as várias discussões atualmente vivenciadas dentro dos conceitos de produção do espaço, esbarra-se sob uma ótica capitalista, a crise do processo de acumulação, bem como a expansão da propriedade privada, fazendo da cidade uma mercadoria a ser vendida (CARLOS, SOUZA e SPOSITO, 2011).

Contudo, o espaço é produzido socialmente, assim se faz necessário evidenciar seus agentes produtores do espaço, de acordo com Carlos (2011):

O Estado, como aquele da dominação política; o capital, com suas estratégias objetivando sua reprodução continuada (e aqui nos referimos às frações do capital, o industrial, o comercial e o financeiro e suas articulações com os demais setores da economia, como o mercado imobiliário); os sujeitos sociais que, em suas necessidades e seus desejos vinculados à realização da vida humana, têm o espaço como condição, meio e produto de sua ação (Grifo nosso) (CARLOS, 2011, p. 64).

Destaca-se o Estado nesse processo de produção do espaço, com o papel de ordenar o território nos seus arranjos e estruturas, viabilizando áreas para a materialização da estrutura espacial. Assim, de acordo com Damiani (1993, p.79), “A construção de conjuntos (habitacionais) se configurava como um projeto estatal, pelo caráter de controle do espaço dos conjuntos, seu maior potencial de manipulação política, de tutela". Assim, o Estado é o precursor e principal agente destas ações, com o discurso que contempla o cunho social.

Além das políticas habitacionais, tem-se que a construção destes conjuntos é uma forma de o Estado dominar e controlar a população de baixa renda em um espaço longe dos chamados centros urbanos e distante também dos locais de discussões de seus direitos. (DAMIANI, 1993). 
No entanto, o Estado não age de maneira isolada, os interesses do capital ficam evidenciados em áreas não valorizadas e reservadas a especulação imobiliária, que posteriormente e articuladas, serão utilizadas nos projetos, tendo assim um aumento significativo do valor de uso desses territórios.

Assim, o espaço começa a impor certas contradições compostas pela ideia, trazida pelos citados autores, de "espaço-mercadoria", o que por si só pode representar movimento nocivo, já que consigna fonte de diversas formas de preconceito, tidos como inconcebíveis.

A geografia, nesse diapasão, se apresenta como uma importante ferramenta de estudo e pensamento que seja capaz de entender a reprodução do espaço urbano em várias nuances e, a partir dessa construção sistêmica de estudo, permitir a redução dos sentimentos contraditórios exprimidos deste espaço produzido pela sociedade através do processo de urbanização.

Categoricamente, Costa (2011, p. 199) traz que

$O$ processo de urbanização brasileira é um fenômeno que ocorreu recentemente. A urbanização deve ser entendida como um processo social e espacial no qual a população rural é levada a deixar o campo para morar na cidade (esse processo ocorre também das cidades menores para cidades maiores) e, nela, ter de enfrentar suas contradições (COSTA, 2011, p. 199).

Seguindo essa linha, imperioso destacar que a cidade, dentro da amplitude do chamado espaço urbano, objeto de inúmeras discussões quando o foco é a análise da organização da população na vida em sociedade, é considerado um espaço político e sociocultural, apontada como centro da organização da sociedade e da economia. (MONTE-MÓR, 2006).

Busca-se o conceito também de cidade, pois é nela que se detectam várias possibilidades de ocorrência da materialização das contradições aqui tratadas, bem como ainda dos preconceitos igualmente trabalhados.

Cumpre trazer à tona a forma com que Monte-Mór (2006, p. 10) define a cidade,

\footnotetext{
Legalmente, no Brasil, as cidades são definidas pelos perímetros urbanos das sedes municipais, e os territórios e populações considerados urbanizados incluem os perímetros das vilas, sedes dos distritos municipais. Entretanto, as áreas urbanizadas englobam amplas regiões circunvizinhas às cidades cujo espaço urbano integrado se estende sobre territórios limítrofes e distantes em um processo expansivo iniciado no século XIX e acentuado de forma irreversível no século XX (MONTE-MOR, 2006, p. 10).
}

Dentro dessa concepção de cidade, tem-se que demonstrar as nuances relacionadas aos temas de "centro e centralidade" para se conseguir demonstrar a sua correlação com os problemas dos conjuntos habitacionais em Ituiutaba/MG.

Tais discussões acerca destas temáticas são de grande destaque e importância na discussão da Geografia Urbana. Enquanto o centro é tido por aquilo que está contido no território, a centralidade se mostra através daquilo que se movimenta no território (SPOSITO, 2001b). 
Deste modo, ao verificar que existe um simbolismo na centralidade em detrimento do centro, bem como o fato de ser o este um ponto fundamental para a manutenção das cidades, a realidade urbana pode ser verificada como o espaço para onde tudo é atraído, destacando-se as coisas, obras e pessoas (LEFEBVRE, 1999).

Além da discussão sobre centro e centralidade, mister se faz analisar ainda a questão da acessibilidade dentro do cenário das cidades.

Segundo o Ministério das Cidades a acessibilidade é declinada para,

Garantir a possibilidade do acesso, da aproximação, da utilização e do manuseio de qualquer ambiente ou objeto. Reportar este conceito às pessoas com deficiência também está ligado ao fator deslocamento e aproximação do objeto ou local desejado. Indica a condição favorável de um determinado veículo condutor que, neste caso, é o próprio indivíduo, dentro de suas capacidades individuais de se movimentar, locomover e atingir o destino planejado (BRASIL, 2006, p. 18).

Sobre o mesmo tema, Ribeiro Filho, Alves e Alves $(2012$, p. 166) ressaltam que,

Nos remete a uma reflexão profunda sobre a cidade em todos os seus aspectos, com destaque para a infraestrutura viária, modos de transportes, edificações, mobiliários e equipamentos urbanos, os quais devem possibilitar que as pessoas usufruam da cidade de maneira igualitária, tendo acesso a todos os bens e serviços (RIBEIRO FILHO, ALVES e ALVES, 2012, p. 166).

Diante de tais apontamentos, vê-se que estão initmamente ligados os conceitos de centro, centralidade e acessibilidade, já que as cidades, tidas como local de interação entre o homem e o capital, devem representar, como já citado supra, além da possiblidade habitação, lazer, trabalho, devem ainda propiciar toda infraestrutura necessária para mantença de uma digna sobrevivência.

Não obstante isto, nas cidades da contemporaneidade observa-se uma acessibilidade meramente simbólica. Claramente destaca-se, através da dimensão de classes, uma territorialização e privatização dos espaços públicos urbanos. A apropriação dos espaços tem sido cada vez mais seletiva, quando na verdade deveria se apresentar mais acessível a todos (SERPA, 2004).

Segundo o mesmo autor (2004, p. 27),

Nas grandes cidades do Brasil e do mundo ocidental, a palavra de ordem é, portanto, de investir em espaços públicos "visíveis", sobretudo os espaços centrais e turísticos, graças às parcerias entre os poderes públicos e as empresas privadas. Estes projetos sugerem uma ligação clara entre "visibilidade" e espaço público. Eles comprovam também o gosto pelo gigantismo e pelo "grande espetáculo" em matéria de arquitetura e urbanismo. De uma forma deliberada, os novos parques públicos se abrem mais para o "mundo urbano exterior" e se inscrevem num contexto geral de "visibilidade completa" e espetacular (SERPA, 2004, p. 27). 
Ocorre que, os investimentos vistos nos espaços públicos tratados por Serpa (2004), não necessariamente abrangem a todos e acabam por privilegiar uma camada social específica, a saber,

\begin{abstract}
Atualmente, a política habitacional que visa solucionar o problema da moradia para a população é o Programa "Minha Casa, Minha Vida". Este foi lançado pela Lei no 11.977 de julho de 2009, cuja finalidade apresentada em seu primeiro artigo é "criar mecanismos de incentivo à produção e aquisição de novas unidades habitacionais ou requalificação de imóveis urbanos e produção ou reforma de habitações rurais, para famílias com renda mensal de até $\mathrm{R} \$ 4.650,00$ (quatro mil, seiscentos e cinquenta reais)" (BRASIL, 2009).
\end{abstract}

Neste caso, é nítido que o fato de o centro ser distante, bem como ainda o fato de não haver a básica infraestrutura, não tem impedido de o Estado convalidar estes espaços como residenciais, na forma de conjuntos habitacionais. Estas políticas se mostram demasiadamente segregadoras para a população que necessita (LIMA, 2013).

\title{
RESULTADOS E DISCUSSÕES
}

Após a realização do trabalho de campo, podemos constatar a realidade dos novos conjuntos habitacionais de Ituiutaba em relação à oferta de serviços e equipamentos públicos nestes locais. A seguir apresentaremos os dados referentes a cada bairro, onde se analisa a presença de unidades de ensino (creche, ensino fundamental, ensino médio), unidades de saúde, espaços de lazer, acessibilidade, transporte coletivo, além de pontos de comércio. Também foram medidas, em cumprimento, as distâncias geográficas percorridas pelas pessoas no caso da não existência destes serviços no próprio bairro.

\section{Conjuntos Habitacionais: Canaã I e II, Buritis, e Nadime Derze I e II}

Esses conjuntos estão localizados na porção leste da cidade de Ituiutaba, os Residenciais Canaã I e II foram criados no ano de 2009 com 1010 casas, o Residencial Buritis criado em 2009 com 328 unidades, e os Residenciais Nadime Derze I e II no ano de 2013 com 580 casas (FERREIRA e MOURA, 2013), esses bairros se localizam aproximadamente de 3,8 a 4,6 km de distância do centro da cidade. $O$ quadro 1,2 e 3 trazem os dados sobre a oferta de serviços e equipamentos públicos nestes bairros.

Quadro 1 - Dados da presença de serviços/equipamentos públicos nos residenciais Canaã I e II.

\begin{tabular}{|c|c|c|c|}
\hline Serviços/Equipamentos & Existe? & Mais próximo & Distância \\
\hline Creches & $\begin{array}{c}\text { Creche } \\
\text { Municipal }\end{array}$ & - & - \\
\hline
\end{tabular}




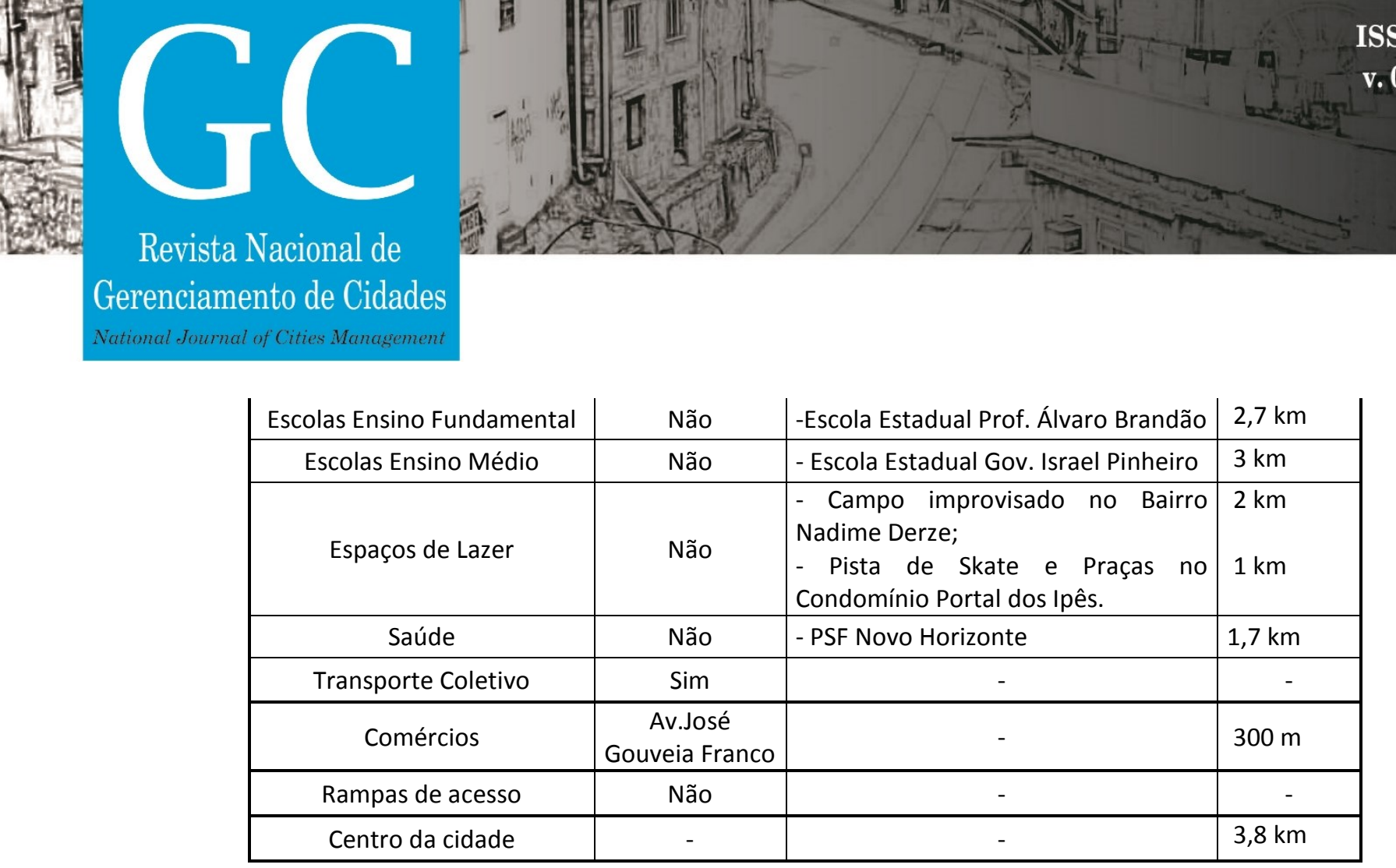

Fonte: Trabalho de Campo (2015). Org.: Daniel de Araujo Silva (2015).

Quadro 2 - Presença de serviços/equipamentos públicos no Residencial Buritis.

\begin{tabular}{|c|c|c|c|}
\hline Serviços/Equipamentos & Existe? & Mais próximo & Distância \\
\hline Creches & Não & - Creche Municipal no Bairro Canaã & $500 \mathrm{~m}$ \\
\hline Escolas Ensino Fundamental & Não & - Escola Estadual Prof. Álvaro Brandão & $2,3 \mathrm{~km}$ \\
\hline Escolas Ensino Médio & Não & - Escola Estadual Gov. Israel Pinheiro & $2,4 \mathrm{~km}$ \\
\hline Espaços de Lazer & Não & $\begin{array}{l}\text { - Campo improvisado no Bairro Nadime } \\
\text { Derze; } \\
\text { - Pista de Skate e Praças no Condomínio } \\
\text { Portal dos Ipês. }\end{array}$ & $\begin{array}{l}1,15 \mathrm{~km} \\
700 \mathrm{~km}\end{array}$ \\
\hline Saúde & Não & - PSF Novo Horizonte & $1,08 \mathrm{~km}$ \\
\hline Transporte Coletivo & Sim & - & - \\
\hline Comércios & Não & - Av. José Gouveia Franco & $100 \mathrm{~m}$ \\
\hline Rampas de acesso & Sim & - & - \\
\hline Centro da cidade & - & - & $3,7 \mathrm{~km}$ \\
\hline
\end{tabular}

Fonte: Trabalho de Campo (2015). Org.: Daniel de Araujo Silva (2015). 


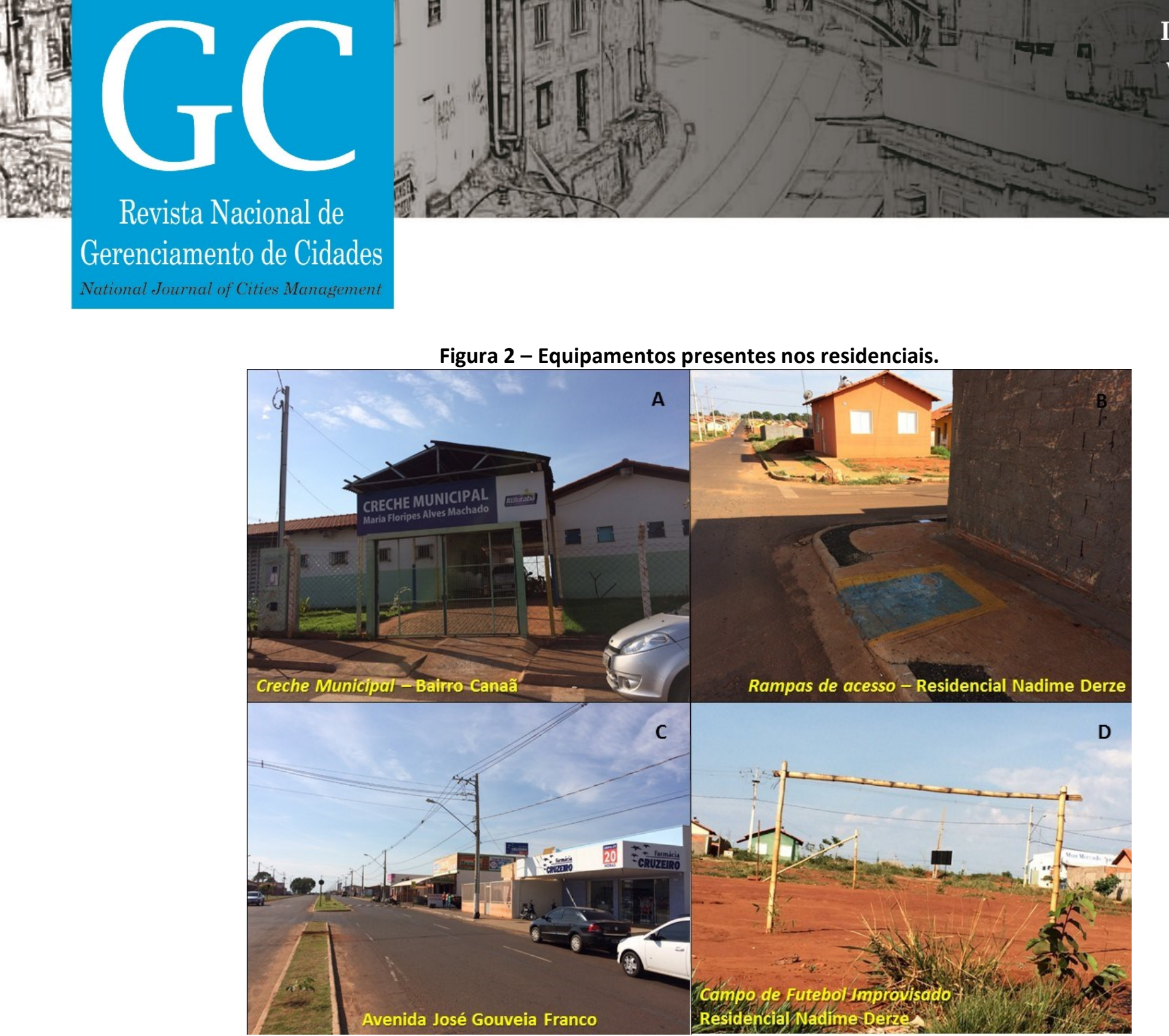

Autor: Fausto Amador A. Neto (2015). Org.: Daniel de Araujo Silva (2015).

Em sua estrutura, ficou evidenciado um novo formato quanto à produção dos novos conjuntos habitacionais, é notada a presença de instrumentos de acessibilidade em suas calçadas, bem como rampas de acesso para cadeirantes (Figura 2B), o que demonstra um indício de preocupação com a inclusão no quesito da acessibilidade urbana.

Seguindo com a análise, o próximo item observado foram os espaços de lazer. Estes não foram encontrados em nenhum destes bairros, no entanto, detectou a ação da comunidade local em produzir seu próprio local de lazer, no caso, um campo de futebol improvisado com estrutura precária (Figura 2D) no bairro Nadime Derze, sendo este o único "local de lazer" mais próximo dos bairros naquele setor. Dos bairros analisados, se um morador do bairro Canaã quiser praticar atividades de lazer, ele deverá percorrer uma distância aproximada de $2 \mathrm{~km}$. No entanto, para todos os conjuntos habitacionais devem existir áreas destinadas aos equipamentos públicos, onde devem ser erguidas estruturas para tal, porém nos locais existem apenas os espaços vazios. Contudo, existem praças e uma pista de skate mais próxima neste setor, porém, estes equipamentos estão localizados em um condomínio "semi-fechado" com guarita e portaria, o que dificulta ou inibe o acesso das pessoas de fora a esses locais de lazer. Nesses conjuntos habitacionais não existem unidades de saúde, sendo que a mais próxima é um PSF (Programa de Saúde da Família) localizada no Bairro Novo Horizonte, a cerca de 1,08 a 2,4 km de distância. 
A atividade comercial presente nestes bairros se apresenta através de pequenas mercearias, porém, na Avenida José Gouveia Franco (Figura 2C), que dá acesso a todos os bairros em questão, é mais dinâmica, contendo uma gama diversa de atividades comerciais, como padaria, supermercados, pet shops, lojas de materiais de construção, dentre outros. Entretanto, serviços importantes como serviços bancários, administrativos e órgãos públicos não são encontrados no local, sendo encontrados apenas na área central da cidade.

Dentre os elementos investigados, o transporte coletivo foi o único serviço que perpassa por todos esses bairros, visto que os mesmos contam com duas linhas, que circulam diariamente abrangendo os cinco bairros aqui analisados. Destacamos aqui a importância deste serviço, pois devido a distância destes bairros em relação ao centro, o transporte coletivo se torna o principal meio de transporte para esses moradores em seu deslocamento na cidade.

\section{Conjunto Habitacional: Marcondes Bernardes}

O conjunto habitacional Marcondes Bernardes encontra se também na porção Oeste da cidade a entrega aos moradores se deu no ano de 2015 , possuindo aproximadamente $4,5 \mathrm{~km}$ do centro da cidade. $O$ quadro 6 evidencia os dados da estrutura encontrada no presente bairro.

Quadro 6 - Presença de serviços/equipamentos públicos no Residencial Marcondes Bernardes.

\begin{tabular}{|c|c|c|c|}
\hline Serviços/Equipamentos & Existe? & Mais próximo & Distância \\
\hline Creches & Não & - & - \\
\hline $\begin{array}{l}\text { Escolas Ensino } \\
\text { Fundamental }\end{array}$ & Não & $\begin{array}{l}\text { - Escola Municipal Manoel Alves Vilela } \\
\text { (até 9o ano) no Bairro Pirapitinga }\end{array}$ & $2,3 \mathrm{~km}$ \\
\hline Escolas Ensino Médio & Não & $\begin{array}{l}\text { - Escola Estadual Cel. Tonico Franco no } \\
\text { Bairro Platina }\end{array}$ & $2,8 \mathrm{~km}$ \\
\hline Espaços de Lazer & Não & $\begin{array}{l}\text { - Campo de Futebol improvisado no Bairro } \\
\text { Pirapitinga } \\
\text { - Quadra de esportes (Deteriorada), no } \\
\text { Bairro Lagoa Azul II }\end{array}$ & $\begin{array}{l}500 \mathrm{~m} \\
300 \mathrm{~m}\end{array}$ \\
\hline Saúde & Não & - & - \\
\hline Transporte Público & Sim & - Bairro Lagoa Azul II & $500 \mathrm{~m}$ \\
\hline Comércios & Sim & $\begin{array}{l}\text { - Avenida Napoleão Faissol } \\
\text { - Avenida Dr. Omar Diniz }\end{array}$ & $\begin{array}{l}2,2 \mathrm{~km} \\
2,3 \mathrm{~km}\end{array}$ \\
\hline Rampas de acesso & Sim & - & - \\
\hline Centro da cidade & - & - & $4,5 \mathrm{~km}$ \\
\hline
\end{tabular}

Fonte: Trabalho de Campo (2015). Org.: Daniel de Araujo Silva (2015).

Infere-se que no bairro Marcondes Bernardes (Figura 3) não há creches, escolas de ensino fundamental e médio, espaços de lazer e/ou saúde, sendo ainda que o sistema de transporte e comércio também seguem o mesmo padrão, porém com distâncias diferentes. 


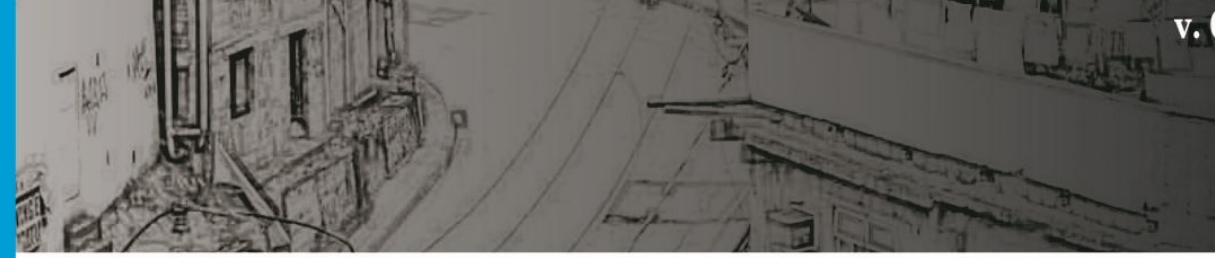

Figura 3 - Vista Parcial do residencial Marcondes Bernardes.

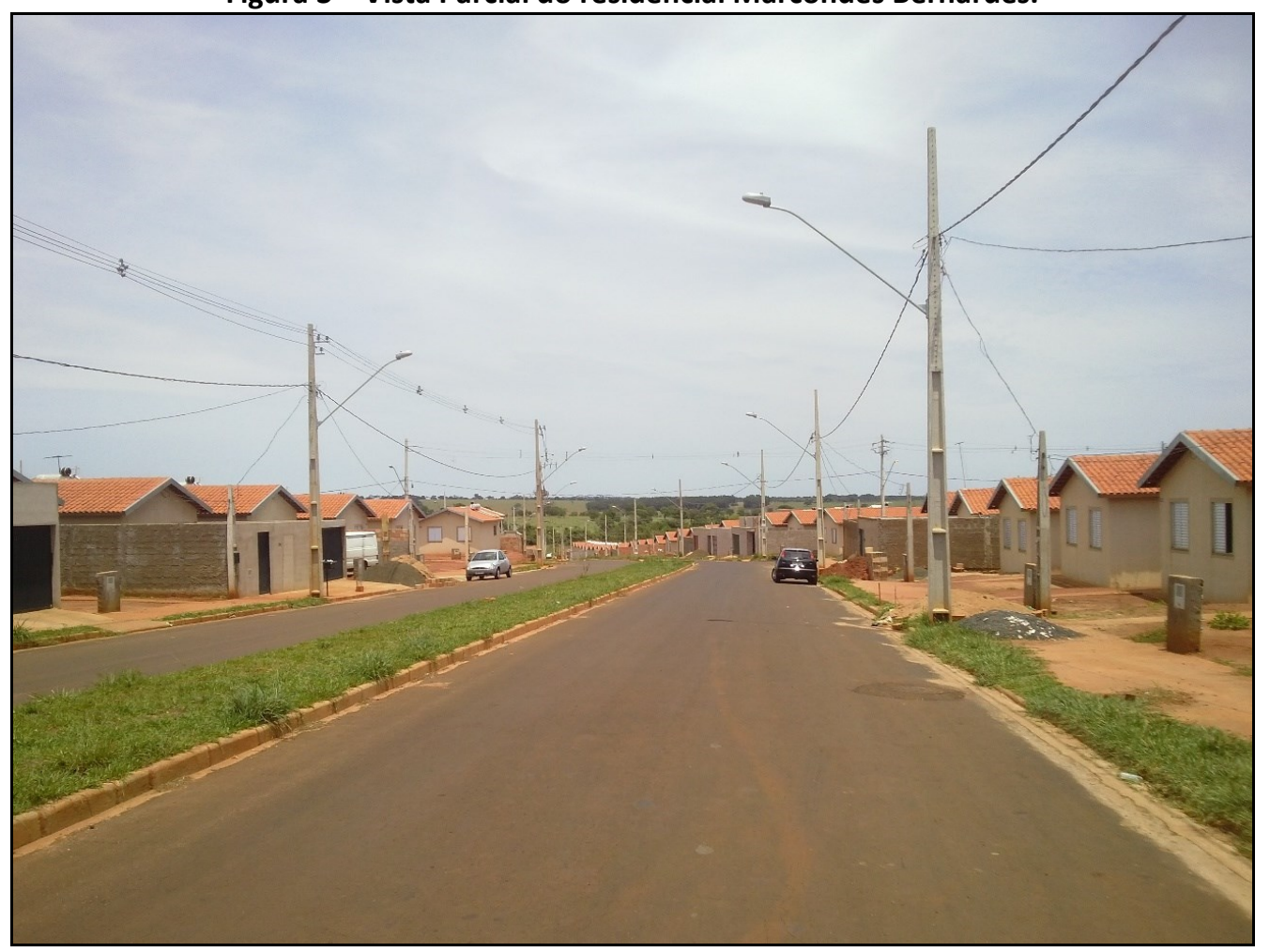

Autor - Fabio Reis Venceslau (2015).

O que deve ser considerado neste residencial é que, diferente dos demais, aqui se encontra rampas de acesso, promovendo assim o que determina a legislação em vigor, promovendo a tão famigerada "acessibilidade".

Posto isto, deve-se considerar a importância de se estabelecer "subcentros" que propiciam aos moradores de bairros mais distantes uma atenuação às suas necessidades, como se configura a Avenida Napoleão Faissol, que em partes supre as necessidades mais básicas destes moradores.

$\mathrm{Na}$ verdade, neste caso, o que deveria ser feito, é a implementação de novos serviços que pudessem atender de modo mais eficaz a população afastada do centro da cidade.

Quanto à saúde, mister se faz repensar a forma de (re) distribuição dos serviços de PSF e UBS, que devem se fazer mais próximas dos indivíduos, desafogando assim as unidades sobrecarregadas de outros bairros.

Ressalta-se que o bairro Lagoa Azul II, criado há 25 anos, é exemplo de conjunto habitacional que fora implantando em descontinuidade da malha urbana, apontando-se o discurso de que logo a "cidade chegaria" até ele, o que não ocorreu durante este período. Ao contrário, verifica-se que até os dias atuais o bairro, que foi estigmatizado por anos, sendo considerado um bairro com violento, ainda é precário quanto aos serviços mais básicos, e agora com os novos bairros ao lado, deve-se viver a mesma realidade. 


\section{CONSIDERAÇÕES FINAIS}

Tendo como base as discussões levantadas anteriormente, percebe-se que os bairros que atendem o programa "Minha Casa Minha Vida", direcionados pelos agentes produtores do espaço, neste caso o Estado, configuram-se como uma nova projeção da (re)organização do espaço urbano tanto no cenário brasileiro, como na realidade da escala local.

Dentre desse contexto, na busca desse processo de reprodução do espaço, tem-se notado a promoção da descontinuidade da malha urbana e, via de consequencia, a expansão em áreas geograficamente afastadas, promovendo o "distanciamento da cidade" em detrimento das movimentações do centro.

Ademais, além de se destacar a distância promovida em acesso a serviços para os moradores desses novos residenciais, aponta-se que o transporte público ofertado não consegue atender as demandas em sua totalidade. Embora tenha a oferta do serviço, percebe-se que não foram disponibilizados novos carros e linhas para atendimento, mas sim uma reestruturação das já existentes, provancando uma sobrecarga do serviço, que não consegue socorrer a contento todas as áreas atendidas.

Nesse patamar, as dicussões voltadas às estruturas desses novos bairros, que criados para atender políticas soiciais vinculadas ao caráter habitacional, se distanciam de alguns outros preceitos fundamentais, como saúde, educação, cultura, desporto e lazer.

Assim, nota-se que os equipamentos urbanos não se consolidaram nestes espaços, ocasionando enormes prejuízos ao seu direito básico de habitação com dignidade.

Desta forma, as novas configurações espaciais obtidas por essa realidade hoje vivenciada, é um problema enfrentado pelo modelo criado para atender os anseios da população carente de habitação.

Por fim, denota-se que o modelo criado, embora seja considerado como um programa recente, que tem como cunho resolver de forma rápida as quesões sociais, acabam se materializando de forma muito ágil e, muitas vezes, ineficaz. Logo, dada a velocidade imprimida nesta materialização do programa, os serviços dispostos não cosenguem atingir os seus objetos mais intrínsecos, promovendo tão somente a moradia, sem se preocupar com os demais serviços públicos essenciais.

\section{AGRADECIMENTO}

Agradecemos a agência de fomento CAPES pelo apoio dado as nossas pesquisas, propiciando assim a partcipação neste evento. 


\section{REFERÊNCIAS}

BRASIL. Construindo uma Cidade Acessível. Caderno 2. Ministério das Cidades. Brasília - DF. (2006). Disponível em: $<$ http://www.cidades.gov.br/ images /stories/ ArquivosSEMOB/ Biblioteca /BrasilAcessivelCaderno02.pdf >. Acesso em: 28 nov. 2015.

CARLOS, Ana Fani Alessandri. Da "organização" à "produção" do espaço no movimento do pensamento do pensamento geográfico. In: CARLOS, Ana Fani Alessandri; SOUZA, Marcelo Lopes de; SPOSITO, Maria Encarnação Beltrão (org.). A produção do espaço urbano: agentes e processos, escalas e desafios. São Paulo: Contexto, 2011. p. 53-73.

CORRÊA, R. L. O espaço urbano. 4. ed. São Paulo: Ática. 2005.

COSTA, R. A. Riscos Ambientais em cidades pequenas do Cerrado Brasileiro. In: SEABRA, G. F. (Org.). Educação Ambiental no Mundo Globalizado: uma ecologia de riscos, desafios e resistências. Joao Pessoa: EdUFPB, 2011. P. 199-214.

DAMIANI, A. L. A Cidade (des)ordenada: concepção e cotidiano do conjunto habitacional Itaquera I. 1993. Tese (Doutorado em Geografia), Universidade de São Paulo, 1993.

FERREIRA, Leilaine de Fátima; MOURA, Gerusa Gonçalves. A produção do espaço urbano: a moradia popular na cidade de Ituiutaba-MG. II SEURB (2013). Disponível em:

<http://www.fecilcam.br/anais/ii_seurb/documentos/ferreira-leilaine-de-fatima>. Acesso em: 01 dez. 2015.

LEFEBVRE, H. A revolução urbana. Tradução: Sergio Martins. Belo Horizonte: Editora UFMG, 1999, $178 \mathrm{p}$.

A Revolução Urbana. Belo Horizonte: Editora UFMG, 2010.

LIMA, I. O. Conjuntos habitacionais e segregação socioespacial: o distrito industrial de Campinas/SP (DIC). Dissertação (Mestrado em Geociências). Universidade Estadual de Campinas, 2013.

MENDONÇA, F. Riscos, Vulnerabilidade e abordagem socioambiental urbana: uma reflexão a partir da RMC e de Curitiba. Desenvolvimento e Meio Ambiente, n. 10, p. 139-148. Paraná: Editora UFPPR. jul./dez. 2004.

MONTE-MÓR, R. L. O que é o urbano, no mundo contemporâneo. Revista Paranaense de Desenvolvimento. Curitiba, n. 111, p.09-18, jul./dez., 2006.

RIBEIRO FILHO, V.; ALVES, P.; ALVES, L. A. Mobilidade e acessibilidade urbana com foco nas pessoas com mobilidade reduzida. In: RIBEIRO FILHO, V.; ALVES, L. A. (Org's). Reflexões Geográficas: diferentes leituras sobre o urbano. Uberlândia: Edibrás, 2012. p. $165-174$.

SERPA, A. Espaço Público e acessibilidade: notas para uma abordagem geográfica. GEOUSP - Espaço e Tempo, São Paulo, № 15, p. 21 - 37, 2004. Disponível em:

<http://www.geografia.fflch.usp.br/publicacoes/Geousp/Geousp15/Artigo2.pdf>. Acesso em: 27 Nov. 2015.

SILVA, D. A. Por entre ruas e calçadas: acessibilidade na área central de ltuiutaba-MG. 2014. 144 f. TCC (Graduação) - Curso de Geografia, Faculdade de Ciências Integradas do Pontal (FACIP), Universidade Federal de Uberlândia (UFU), Ituiutaba (MG), 2014. Disponível em:

<http://www.facip.ufu.br/sites/facip.ufu.br/files/Anexos/Bookpage/Daniel de Araujo Silva.pdf>. Acesso em: 28 Maio 2015.

SPOSITO, M. E. B. Novas formas comerciais e redefinição da centralidade intra-urbana. In: . (Org.). Textos e contextos para a leitura geográfica de uma cidade média. Presidente Prudente, 2001b, p.235-253. 